\title{
En las colinas, las ciudades. Representación politica y naturalización del mandato
}

In the bills, the cities. Political representation

and naturalization of the mandate

Ricardo Gutiérrez Aguilar

Universidad Complutense de Madrid ricargut@ucm.es

DOI: http://doi.org/10.15366/bp2019.20.006

Bajo Palabra. II Época. No20. Pgs: 107-124 


\begin{abstract}
Este trabajo se enmarca en el proyecto postdoctoral de investigación On the letter and spirit of imitation: Exemplum and Exemplarity (2018-2020), adscrito al Departamento de Lógica y Filosofía Teórica (Facultad de Filosofía, Universidad Complutense de Madrid

- UCM) y bajo la supervisión del Prof. Dr. Ricardo Parellada. Vienen a sumarse sus resultados científicos a los generados dentro de los proyectos PAIDESOC - El desván de la razón: cultivo de las pasiones, identidades éticas y sociedades digitales (FFI2017-82535-P), dirigido por la Profa. Concha Roldán Panadero (Instituto de Filosofía - CSIC) y la Profa.

María G. Navarro (Universidad de Salamanca - USAL), y el proyecto de innovación educativa de la Universidad Complutense de Madrid Contrapicados y puntos de fuga: otras historias de la historia de la Filosofía (PIMCD169), dirigido por la Profa. Nuria Sánchez Madrid (Departamento de Filosofía y Sociedad - UCM).
\end{abstract}

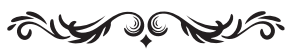

\section{Resumen}

La representación política en Thomas Hobbes es cuestión de nuda designación. Un ejercicio con el lenguaje. El movimiento básico dentro del cuerpo de la Commonwealth es la designación de un oficial para el pueblo. Esta articulación teorética no es sin embargo suficientemente desarrollada. El objetivo del presente trabajo es sacar provecho de la ayuda que la cuádruple taxonomía sobre representación de A. P. Griffiths y R. Wollheim ofrece, y de la elucidación que presenta Michäel Foessel en torno a lo que es intimo frente a lo que es privadollo que es público, empleando ambas como instrumentos que pueden arrojar algo de luz a las intuiciones fundamentales de Hobbes reunidas en su obra principal, el Leviathan.

Palabras Clave: Representación politica, Hobbes, A. P. Griffiths, R. Wollheim, M. Foessel, Privacidad, Intimidad

\section{Abstract}

Political representation in Thomas Hobbes is a matter of bare designation. An exercise with language. The basic movement within the body of the Commonwealth is to appoint someone as officer for the people. This theoretical articulation is not sufficiently developed though. The aim of the present text is to profit from the help the four-fold taxonomy on representation by A.P. Griffiths and R. Wollheim offers, and of the ellucidation Michäel Foessel presents around what is intimate before what is privatelwhat is public, as instruments that could shed some light onto the fundamental intuitions Hobbes gathered in his main work, the Leviathan.

Keywords: Political Representation, Hobbes, A. P. Griffiths, R. Wollheim, M. Foessel, Privacy, Intimacy 
Natura (arte por el que Dios ha ejecutado y gobierna el mundo) es por industria [art] del ser humano, asi como en tantas otras cosas, imitada en esto de igual manera, de modo que le es dado a aquél fabricarse un animal artificial. Pues vista así, la vida no es sino movimiento de miembros, el principio del cual no deja de ser en lo fundamental uno de origen interno; y es que ¿por qué no habríamos de decir en ese caso que todo autómata (ingenio que se mueve por si solo gracias a resortes y ruedas como lo hace el reloj) posee vida artificial? [...] Pero el arte viene a llegar incluso más lejos, en lo que imita esa que es la obra racional y más excelsa de la Naturaleza, el propio ser humano. Pues es por arte también que se crea el gran Leviatán que llamamos República [Commonwealth], o Estado..."

Thomas HobBes, Introducción al Leviathan ${ }^{1}$

\section{Naturaleza, ciudad y designatio}

Dice Hobbes del 'GRAN LEVIATÁN' en lo que lo propone como entrada a su obra que viene a ser este una arriesgada emprendeduría compuesta a partes iguales de materia [Matter], forma [Forme] y poder [Power $]^{2}$. Un mecano ensamblado a piezas.

Empresa arriesgada porque remeda 'further' [más allá] la obra de Dios. Cuando se pone uno a imitar, puede ser más o menos humilde en sus intentos. Así, sea que esta intentona columbre alturas y fuerzas superiores en todo a la del común de los mortales en soledad, no deja el ingenio de ser un todo hecho de partes. Un todo

\footnotetext{
${ }^{1}$ Hobbes, T., "The Introduction", en Leviathan, edited with an introduction and notes by Gaskin, J. C. A., Oxford, Oxford University Press, 1998, p. 7. El fragmento es de mi propia traducción. En esta cuestión, dos apuntes se hacen necesarios. El primero es la ambivalencia del término 'art' empleado por Hobbes. El autor se refiere por igual a aquello que se hace o fabrica-industria-donde lo decisivo es la ejecución productiva, y se refiere asimismo con dicho término al carácter original del producto en comparación al derivado que le correspondería -arte frente a simulación e imitación-. Hemos pretendido en nuestro ejercicio de traducción reflejar de algún modo no sólo su ambivalencia sino su uso distintivo. Hay que decir también que la obertura del texto directriz de Hobbes menciona la Commonwealth pero al equipararla con la forma 'Estado' en la misma línea hemos creído más conveniente convertirla en ese caso en República, la cosa pública como riqueza común al abasto -common wealth, res publica. En relación con estas cuestiones de técnica y artesaia racional vid. Malherbe, M., Thomas Hobbes ou l'oeuvre de la raison, Paris, J. Vrin Librairie Philosophique, 2000.
}

2 Hobbes, T. Op.cit., p. 1 
orgánico, eso sí. Las dificultades están pues en medir las distancias entre lo orgánico y lo natural según presenta el fragmento. La forma mística del cuerpo organizaría lo material, se descargaría en sus impulsos en lo que va imitando. Esto es, de manera delegada. Mira el modelo y pretende simular lo que allí descubre. Simula vida, y el juicio es severo cuando hay vida original con respecto a la cual realizar las comparaciones. $\mathrm{Y}$ es que puestos a comparar, donde una se perfunde por la carnosa bomba, la otra tiene por corazón apenas un muelle $[s p r i n g]$ que devuelve choques inelásticos; donde la otra inquieta a los nervios, tiene ésta tantos alambres [strings] para que le hagan el aguante; y si de mociones hablamos, ya sean cuadrúpedos o bípedos implumes son aquí dentados engranajes [wheels] los que se van arrastrando... ${ }^{3}$. Ante cierta perspectiva, si no supiéramos que el intento es serio lo tacharíamos de parodia de la Naturaleza. El reflejo que devuelve Natura convierte el homenaje que el arte le realiza casi en hipócrita si lo miramos con severidad. Un mecanismo ocurrente acaso, pero en nada ingenioso. Pues la marca del genio no es otra sino la originalidad, y lo verdaderamente original aquí sería la vida propiamente dicha [proper life]. Frente a ésta, el arte que es industria, fábrica y artificio, incluso cuando queda legitimado es un gesto torpe versus natura. Los parecidos aquí son odiosos. Dice Hobbes de Dios que ejecuta y gobierna -nos confiesa así de pasada. Traducido al lenguaje castrense: ordena y manda. En el ordenar manda. Sin dilación, sin mediación. Utiliza el de Westport los inequívocos verbos to make y to govern puesto que en su originalidad el Creador no sólo administra -lo cual daría ocasión a preguntar siquiera aquello que es propiedad de quien administra y diferir la autoría entonces como hipótesis- sino que hace, pero hace como el que hace con las manos [to make]. Con fuerza, con power. Porque lo que administra es lo que crea él mismo. Lo que amasa directamente. Por eso su Matter y su Forme no contradicen a su Power. Lo que el Primer Agente hace es por eso mismo su propiedad en tanto creatura. Es el animal original que bautizamos de 'mundo'. Un animal compuesto, con miembros, pero sin doblez. No tiene pliegues. Es todo de una vez desde dentro [from within]. Como principio. No nos extrañe que una obra así dé para admiraciones e imitaciones. No obstante, como en tantas otras oportunidades, si al ser humano le pica el acicate de la semejanza y entonces no puede por menos que ir a construirse sus propias criaturas, esto lo hace siempre a su manera. El ser humano imita y no crea. Si pone sus manos a ello, la masa que moldea ya recibió la presión de otro. Su 'to make'

\footnotetext{
${ }^{3}$ Ibid., p. 7. Téngase en cuenta el modelo artificial que Hobbes tiene en la cabeza. Hobbes ha leído a Descartes y comulga en lo principal con su visión mecanicista del ingenio del mundo. La res extensa no da para traducciones de los espíritus animales. Mucho menos del fenómeno de lo humano. La visión del inglés de la construcción de la obra de lo público es la de un mecano animado aún así. A este respecto es de utilidad el estudio completo en su génesis de la antropología hobbesiana en comparativa con la fundación del Estado que se puede encontrar en Hoffe, O., Thomas Hobbes: Antropologie und Staatsphilosophie, Freiburg, Universitätsverlag, 1981.
} 
está conducido. El Padre amantísimo lo conduce de hecho, por razones, y quizás por eso mismo es de entre las obras divinas la más excelsa. No lo presiona, lo persuade más bien. La obra devuelve la mirada creadora -y el acto de crear- a su demiurgo

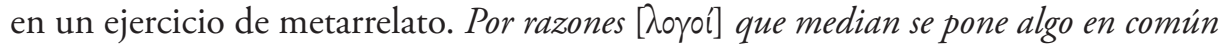
que va en dos sentidos y se inicia un diálogo compartido. Vinculante. Claro está que el resultado no puede ser el mismo. La distancia que relaciona ambas venturas es la de la representación. El Hacedor si se presenta se presenta sin más. Es Aquél que Es. No necesita de valedores. Su palabra es ya gobierno. Natura es arte [nomors] logrado. Realizado por vez primera e inapelable. 'Power', del latín vulgar potere, tiene en el 'Might'su correlato en el inglés arcaico y en el 'Macht' [poder de hacer con las manos también] germano su antecedente. Por eso God is All-Mighty, Todopoderoso. Se olvida uno siempre sin embargo de que el campo semántico de estos conceptos es el de la fuerza física corporal. La intervención directa sin intercesiones es imposición. La clase de institución que se hace por la fuerza ${ }^{4}$.

El ser humano que emula tiene que aspirar el hálito de vida que le ha quedado en sus instrumentos. Para Hobbes esto es el 'arte' [art] propiedad del individuo. Si hace, hace con una potencia prestada. Cuando ve andar solas las manecillas del reloj no debe ocultársele el hecho de que fue porque antes les dio cuerda. El ánimo del reloj es uno delegado. Doblado y espejuelado. Se mueve por otro, y donde habría vita pristina, la hay ahora obscura. Velada. El autómata debido a eso esconde sus secretos en la panza a fin de preservar la ilusión del artesano. Ilusión de vida original. Juega a que en esa panza se guarda el principio interno del que nos recelamos. Pero descubierto el hueco allí dentro para nuestra desgracia no hay sino resortes y más resortes.

No desesperemos porque la desilusión puede que venga si acaso de que aquí el individuo aún es tímido en eso de la imitación. Falta que se juegue el todo por el todo. Porque -decíamos- hay niveles de arrojo y descaro en lo que se puede copiar. Porque el arte puede incluso llegar más lejos y ser más ambicioso en el ejercicio de imitar a esa que es la obra más excelsa-por racional- en la Naturaleza. El ser humano puede moldear a otro ser humano. Un apunte es necesario porque quizás no se quiere decir con esto lo que uno de primeras imaginaría: el resultado de la imitación lograda no es ni el homunculus de Paracelso ni El Turco que juega al ajedrez de Von Kempelen, que aún está por llegar. Hobbes llama a este producto 'Commonwealth'. El resultado de la imitación más ambiciosa es el Estado, esa criatura que otros llaman civitas, la

\footnotetext{
${ }^{4}$ En Dios la razón que ejecuta y gobierna es, efectivamente, una palabra. Es $\lambda$ óyos [discurso], voz con sentido. Instiladora de vida. Voz anímica. Creadora. Lo que dice el Hacedor es un hacer ya directo. La voz divina es un institutio naturalis. Signo, señal y símbolo son lo mismo bajo el arte por el que Aquél realiza y ordena el mundo. Natura es convención divina.
} 
Ciudad arquetipo como comunidad. La comunidad del bien común es la imitación propia al ser humano. Y en ella es el ser humano mismo el que se itera, no el muelle, el engranaje y la tuerca, que difícilmente lo iban a representar igual de bien. Seres y más seres humanos devolviéndose la semejanza de lo que por natura son es la única forma de hacerle honor a aquél en la imitación. ¿Pero qué son y qué es mientras representan y es representado? ¿Cuál es su nueva Matter and Forme? Bajo el cristal de aumento el Leviatán es muchas cosas, son "los magistrados, y otros oficiales de la judicatura y del ejecutivo, obrando de articulaciones artificiales; los consejeros por los cuales toda cosa de necesidad para el común ha de conocerse y sugerirse, son la memoria; son la equidad y las leyes, una razón y una voluntad artificiales del mismo modo que la recompensa y el castigo (por los cuales bien sujeta [...] cada juntura y elemento es movido en pos de la ejecución de su deber) son los nervios, que como en el organismo natural tienen la misma función; [descendiendo al detalle ahora] la abundancia [wealth] y las riquezas [riches] de cada uno de los miembros participantes, hacen del vigor [strength]; y la salus populi (la seguridad del pueblo) es su negocio" e interés 5 . Son y representan. Lo mismo da. Todo el cuerpo del Estado quiere sobrevivir como fin último, ese es su negocio. Su 'salus' es conservar su sustancia orgánica. Sustancia suficiente para mover recompensas, castigos, abundancia y riqueza en definitiva. $Y$ en pos de este fin supremo ordenador despliegan los diversos miembros sus respectivas artes e industrias. Esta sustancia en equilibrio siempre va y viene de sus circunstancias en torno a proporciones de razón y propósito, cuyas imitaciones son la ley y la justicia -que cada miembro se encuentre ocupando el lugar que le corresponde y teniendo el peso y contrapeso que le vaya de suyo. Así se gobierna la Ciudad. Magistrados y oficiales ejecutan dicho gobierno. Lo llevan a realización conduciendo el dictamen de razón y voluntad a efecto. Lo llevan a cabo como el juego de posibilidades de la articulación del codo o la rodilla y sus palancas que permiten desplazar objetos y desplazarse como un objeto. Guarda la memoria en la representación que dan de ella los consejeros la historia de dichos efectos y dictámenes de razón. Su historia institucional de éxitos y fracasos, acercamientos y alejamientos del vigor y la salud. Matter, Forme y Power quedan encardinados por la imagen repetida del ser humano que se continúa en cada estrato, que se proyecta y se refleja.

La unidad de la civitas, la comunión del cuerpo a organismo, es "la soberanía que no oficia sino de alma artificial" ${ }^{6}$. Soberanía es primero sustancialidad, unidad y orden de los elementos; y quiere ser además principio de movimiento, principio de

\footnotetext{
5 Hobbes, T., op. cit., p. 7

${ }^{6}$ Ídem. La noción de soberanía hobbesiana queda estructurada en torno a un estado de excepción, el del contrato social. Este momento es sobrenatural. Artificial si así se desea. No deja de ser en todo caso ya convencional: para Hobbes el signo es una posesión del individuo humano inscrita en la positividad de la lex naturalis que le corres-
} 
vida, en un segundo término; vida, a su vez, no es sino relación armónica continua entre los miembros de aquella primera unidad. Se ha dicho de la 'salus' [salud] que era el negocio del pueblo. Lo que lo ocupaba. Esta seguridad es de entrada obviamente el estar a salvo de perder su unidad, de perder sus miembros. ¿Pero donde hay unidad, en qué queda entonces la acusación de doblez y pliegue? ¿Será esta una acusación injusta que merezca la persecución y sentencia severa del magistrado? ¿No cabe prometerse con el Leviatán algo más que un mero autómata? ¿La obra de arte definitiva quizás si nos sentimos in the mood? Nada más lejos de la realidad. El autómata es a no dudarlo el más logrado y acabado que la limitada ciencia del ser humano se ve capaz de darse, pero no es ni mucho menos perfecto. Tiene el ingenio sus pliegues. Alberga mecanismo en las tripas y por este sabemos que guarda un hálito de prestado. La doblez no hay que buscarla sino en el acto mismo de su institución como civitas. En el momento fundacional que es cuando las diferencias entre los quehaceres de lo divino y de lo humano se hacen de notar, claro está. Hobbes hace un aparte entre Natura y las leyes que tienen a bien ejecutarla y gobernarla, y la civitas que en vez de a leyes se aviene a contratos, que actúan del signo civil de las voluntades. Cada voluntad representada se pone como compromiso. Por el cual bien sujetos cada juntura y elemento son movidos en pos de la ejecución de su deber. Lo que el ser bumano hace lo hace mediantes signos, pero signos convencionales. Por delegación. Lo que presenta el 'art' en la lex naturalis de forma inmediata es representado con mediación de lo expresado en la técnica de la promesa [promise], del pacto [pact] o del juramento [oath], que son todos artesanías de los individuos en el cumplimiento de su voluntad ${ }^{7}$. Como institución, la de la civitas hay que juzgarla desde el punto de vista del que se da cuenta que dicho acto no se hace con las manos, sino con la palabra. $\mathrm{O}$ al menos del que se da cuenta de que con la palabra no hacen como con las manos. Tienen en ese caso que moverse los miembros en la misma dirección -tienen que decir en el mismo sentido- y los esfuerzos hacia el mismo fin para allegarse al mismo sitio. Y "el único medio para erigir un tal poder en común [...] es, conferir el de cada uno junto con sus fuerzas [su abundancia y riquezas si fuere necesario] a un sólo individuo, o a una asamblea de ellos, que pudiera reducir todas sus voluntades, en la pluralidad de sus voces [de su palabra], a una sola" ${ }^{8}$.

Varias cosas son de notar en el decir de Hobbes. La primera refiere a su cualidad, y es que sólo hay una vía para iterar al ser humano. Una de razón: la representación política. Representar como se debe al individuo humano sólo está al alcance del que por

ponde por derecho divino. vid. Biral, A., "Hobbes: la sociedad sin gobierno", en Duso, G., El contrato social en la filosofía politica moderna, Valencia, Leserwelt, 2002, pp. 51-108.

7 Hobbes, T., Op.cit., pp.86 y ss.

${ }^{8}$ Ibid., p. 114 
un otro se pone presente. Nos vale con decir que con otros elementos de imitación el individuo es irrepresentable, de ahí su excelencia. Sólo una voz vale por otra voz. Ponerse a levantar semejante empresa no es un trabajo de fuerza, sino de translatio. La conversión de unas voces en otras. Unas palabras en otras. La palabra es el vehículo único asimismo de la voluntad. La palabra dada en pacto, contrato o compromiso es la voluntad atada a su deber, es decir, la cesión de la confianza. La confianza es el sistema nervioso -que anticipa recompensas y castigos- que hace vivir a la ciudad. Es una fe en la satisfacción del contrato social. Y esa cesión no deja de ser una confesión que se hace mediante el traslado de lo múltiple a lo único. Una cuestión de cantidad. Hay una reducción pero no del valor. La reducción es una de equivalencia. Muchos valen por uno, muchos importan lo mismo, pero ese uno vale al mismo tiempo por y para todos. Al designar [to appoint], al otorgar mediante signo civil, se consigue que un individuo como magistrado, oficial, consejero sea traducido a la sola persona de la civitas. Una persona a la que se reconoce como a uno mismo [acknowledged as oneself. Del valer se pasa al validar. No sólo importa, además es legitimado. Pasado por ley. Puesto como un cabo del Derecho. No es ningún misterio entonces que para el Hobbes ya camino de esta segunda parte del Leviathan la civitas sea una cuestión finalmente de la palabra y su satisfacción, una cuestión de definición [definition] .

En lo que sigue nos basaremos en las intuiciones teóricas fundamentales hasta aquí presentadas para erigir por nuestra parte un cierto diagnóstico clínico para la salud relativa de un tal cuerpo. Dicha salud decíamos que depende en definitva de cómo se representa. Y, si es que es cierto que la representación política no sólo articula sino que transmite vida y vigor desde y al organismo civil como principio interno, un principio que hace circular la soberanía, puede decirse también no obstante que en no pocas ocasiones el olvido de su carácter de artificio causa artrosis en lo que se desliza equivocadamente hacia su naturalización. En esas ocasiones $e l$ representante olvida el natural del signo de su voz, uno que es el de un mandato, olvida la conferencia de todo lo que sobre las cosas en común puede, y, por último, tiende a olvidar la confesión-la fe depositada como fianza-que aquellos que lo han aupado cifraron para él en la forma del contrato de representación. Para dar rendida cuenta de ello querremos aclarar y no olvidar tal reducción con ayuda del concepto de 'lo intimo' que Michäel Foessel ha articulado desde los de lo público/lo privado, empleándolo en un juego con la cuádruple taxonomía sobre representación política que Allen Phillips Griffiths y Richard Wollheim -auténtica inspiración en este asunto de Hanna F. Pitkin- hicieron clásica hace ya tiempo ${ }^{10}$.

\footnotetext{
9 Ibid., p. 111

${ }^{10}$ Las obras de referencia en este sentido serán Foessel, M., La privación de lo intimo. Las representaciones políticas de los sentimientos, traducción de Jordi Terré, Barcelona, Ediciones Península, 2010 y Griffiths, A. P.; Wollheim,
} 


\section{Representación política discreta, identidad e identificación}

EN LA PALABRA, EN EL SIGNO hUMANo, el hacer se desdobla. Se duplica al colocarse ante el espejo que hace la distancia entre el to do y el to make. En esto no hay ni explicación ni práctica simple. Intentemos rendir por momentos una genealogía del acto de fundación. Porque no hay un solo gesto con un solo significado. Para Foessel una pregunta reveladora del problema con el que nos acabamos de topar sería la siguiente: "Cuando Nicolas Sarkozy pone en escena su vida sentimental con la intención de conmovernos, cuando, en un plató de televisión, Ségolène Royal intenta tocar a un hombre inmovilizado en su silla de ruedas para demostrarle su humanidad, ¿̇tenemos razones para sentirnos políticamente ofendidos?" " ¿'Tenemos razones para sentirnos mal traducidos políticamente? Es decir, se sobreentiende que podríamos sentirnos ofendidos, pero, ¿deberíamos, tendriamos la obligación de sentirnos así? ¿Y qué razones nos asistirían en ello? Sarkozy, Royal, estarían significándose, ¿pero se estarian significando politicamente, es decir, representativamente?

El doble sentido de la palabra -de la voz- 'representación' juega a liarnos en el equívoco aquí. Ese sucedáneo de la presentación tenía que darnos más pronto que tarde algún que otro quebradero de cabeza por su misma naturaleza de delegado. Porque la palabra nos sirve de dos modos como signo civil. Está el modo que busca su satisfacción y cumplimiento, y en éste tendríamos el sentido jurídico del término. La promesa, el contrato, el juramento, me representan. Tendríamos en ello un sentido fuerte como compromiso sujeto a retribución; y estaría también el modo en que la palabra es mediadora en mostrar la doblez y el pliegue del artificio, el mismo juego de espejos del estar por otro u otra cosa. El juego del adentro y el afuera. La libertad de ejercer de imitador y presentarse en la civitas como individuo que imita. Es ese el modo a partes iguales tanto del representante político como del lenguaje teatral, catártico, que sublima las pasiones por el presentarse a escena en el argumento. Ambos modos de representación son modos ciudadanos. La diferencia no está en que ambos sean o no signos para la civitas - que lo son- sino lo que con ellos se intenta expresar en cada caso. Pues son escenarios de lo común ya sea en un plató de televisión, en las páginas de los tabloides o sobre las tablas dispuestas para el drama y la comedia. Dan para plegarse en un afuera y un adentro que artificialmente son el trasunto de lo público y de lo privado de las conciencias.

R., "How Can One Person Represent Another?", en Proceedings of the Aristotelian Society, Supplementary Volumes, vol. 34, 1960, pp. 187-224. La obra clásica sobre teoría de la representación política es la de Hanna Fenichel Pitkin (Pitkin, H. F., The Concept of Representation, Berkeley, Los Angeles - CA, University of California Press, 1972). La inspiración de Pitkin puede encontrarse en los trabajos de Griffiths y Wollheim.

11 Foessel, M. Op.cit., p. 8 
La persona es toda entera signo de lo civil. Incluso su privacidad no deja de ser un espacio funcional que aquélla abre en la cosa pública. Y sí, no hay mejor medio para rendir la identificación certera que aquello de la vida sentimental y las labores de lo humano. Nos reconocemos en ellas sin dilación. Sin distancia. Pudiera reducir esto por via de equivalencia todas las voluntades en la pluralidad de sus voces a una sola. Y entonces ya no son más Sarkozy y Royal, sino que son Ségolène y Nicolas. Son como nosotros. ¿Pero es una significación política que plantee los requerimientos de un deber civil? Con su aparente intimidad dispuesta ante nuestros ojos, o, mejor dicho, con la intimidad que compartimos con ellos como iguales puesta ante lo civil como el lugar donde todos coincidimos la cosa parece ir de naturalidades. Y uno es uno mismo, al natural, con no menos intensidad que íntimamente. Así de poderoso es el efecto de la beautiful people. Voces como las de 'sinceridad', 'transparencia', 'autenticidad'son recursos que todo aquél que quiere explicarse de esta manera necesitará sin dudas. Son recursos que acortan la diferencia y la distancia entre representante y representado. La eliminan. Reconocerse es a este punto la respuesta a una demanda de aprobación, no de legitimidad ${ }^{12}$. Una demanda de validación de un valor, no del derecho alegado del mismo. Pero cuando Nicolas y Ségolène nos piden semejante reconocimiento, cuando quieren que nos conmovamos lo suficiente como para confiarnos con ellos, ¿no estarian traduciéndose ya de algún modo como algo antes bien significativamente politico, civil, más que personal e intimo? ¿No sería preciso entonces distinguirlo de otro ejercicio - modo- de reconocimiento? Habremos de hablar entonces de tipos de ofensa. Ofensas dependientes del momento de la institución del representante. Y ofensa sería el no ser reconocido, del mismo modo que el ser mal reconocido, por supuesto. Sentirse políticamente ofendido es tema para la mala traducción de lo político, para los perjudicados por las malas equivalencias. La peor equivalencia es con un cero. Así, y fuera por un momento de la casuística que nos acaba de mostrar Foessel, habría desde luego un primer tipo de representación política en la que se haría cierto que tendríamos motivos de sobra como para sentirnos ofendidos, traicionados en nuestro compromiso, y esto simplemente en virtud de un hecho: que estemos ante esa representación en la que no haya voz alguna para

\footnotetext{
12 Ibid., p. 130. La obra de referencia para discutir tal afirmación no puede ser sino Honneth, A., The Struggle for Recognition: The Moral Grammar of Social Conflicts, translated by Joel Anderson, Cambridge, Polity Press, 2005. Más allá del discurso instituido, Honneth ha ahondado en el fenómeno psicológico y expresivo de tal aprobación y convertido su aparición en lo público en una triangulación natural que se realiza durante la llamada revolución del noveno mes durante la niñez. En esa época se va aprendiendo el espacio de la perspectiva de lo común y se demanda y requiere no sólo aprobación por parte de la persona adulta de referencia, sino legitimación en los propios juicios sobre objetos externos. vid. Honneth, A., Reification: A New Look at an Old Idea, edited by Martin Jay, Oxford, Oxford University Press, 2008. Las conferencias recogidas en este volumen fueron pronunciadas en realidad en marzo de 2005 dentro del ciclo de las Berkeley Tanner Lectures en la University of California, Berkeley.
} 
uno mismo. No hay ninguna equivalencia. A saber, justo cuando no somos representados en absoluto.

Para este tipo del ofenderse legítimo hay sin embargo cura. La conocen bien tanto Sarkozy como Royal. "Este sentido de la representación, en el que una persona [podría] representar a otra [obraría sencillamente en virtud] del ser lo suficientemente parecidas, y lo calificaríamos de representación descriptiva. [En sentido lato] yo sería un representante descriptivo de mi generación -una muestra, un especimen o un análogo- cuando soy lo suficientemente parecido a mi prójimo como para que alguien pueda estar razonablemente seguro a la hora de sacar conclusiones acerca del resto de miembros de mi generación a partir de lo que sabe de mí. Por supuesto que no se me puede convertir en un tal representante. Sólo se puede pensar en mí como uno si de hecho ya lo soy" ${ }^{13}$. Si lo soy de forma natural. No puedo serlo de forma artificial. No es cosa de industrias y embelecos. Naturalmente, por arte de la Natura, soy más que suficientemente análogo de mi prójimo. Así, muchos valen por uno, muchos importan lo mismo. No hay nada que traducir si soy el signo civil idéntico a mi conciudadano, pero sí hay mucho que resarcir si sin mí aquél no cuenta para nada en absoluto. Si sin mí no tiene presencia. Nicolas, Ségolène, quieren mostrar que son lo suficientemente parecidos a sus votantes como para ser designados, para confiar en ellos el monumento de una ciudad que los incluya. Claro que la significación política no pasa aquí de ser discreta. Son meramente identificados como humanos, sujetos de emociones, personas. Y sí, es que sólo había una vía para iterar al ser humano, usar al propio ser humano como herramienta.

La representación descriptiva es el protolenguaje del signo político. El momento en que las cosas sin signo pugnan por ganarse un nombre. De la misma forma que la ostensión y el deíctico lo son para la semántica general, el quorum que hace completo al conjunto de los miembros conductores de la vida política lo es para la significación política. Será el alfabeto. Un alfabeto en su infrarrepresentación hace no sólo del cuerpo del Estado el del tullido, sino que traduce mal a Natura. La designatio es la forma básica de remedio. Designar, conferir, coloca una presencia. La transferencia de la confianza del que nombra: conferir poder y fuerzas a un individuo o a una asamblea de ellos lo suficientemente parecidos a sus semejantes como para dar movimiento al alma artificial de ese autómata común. En el ejemplo, la muestra que describe la parte es explicada por la parte. Pero esta representación no da para mucho más pues lo asignado [what is appointed] queda instituido tanto por alguna razón como en ausencia de razones. Como acto ilocucionario de fuerza significativa. Sólo se puede pensar en el elemento como signo si de hecho ya lo

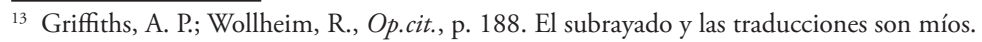


es. También en ausencia de buenas razones, por arbitrio. Aquí véase en ello -por una cuestión de semejanza- por razón de ser una imagen de lo humano. Sin más. La fundación, la institución descriptiva, es la imitación del lenguaje natural. Del signum naturalis. Un algo en lugar de otra cosa que son ambos y a la misma vez irreductibles. Que son primitivos. Pero esta libertad en el ejercicio de la representación da para un segundo tipo de la misma directamente relacionado y análogo del de la descriptiva que nos va a servir de ilustración útil. Porque la muestra, el especimen que sirve de foco de la conferencia de las voluntades, puede significarse ahora en su carácter derivado. En la representación simbólica lo que sucede es que "un individuo [una asamblea de ellos, o un objeto de atención particular], tanto por alguna razón como en ausencia de razones [arbitrariamente, sin norma], es elegido como foco de las actitudes que son pensadas como apropiadas respecto de otra cosa [otro individuo, o una asamblea de los mismos] que no es el mismo individuo" que representa ${ }^{14}$. Es designado [appointed] como centro en torno al cual gira la misma serie de representaciones derivadas que giraban alrededor del signo civil. Arbitrariamente, por convención, lo que vale tanto como decir que se hace artificialmente. Nicolas, Ségolène, buscan justamente esta segunda clase de identificación. No quieren ser señalados o significados como bumanos o sujetos de emociones, como personas que se conmueven como se conmueve su prójimo -esto es trivial, se da por hecho que no son robots- sino concitar-que se les confiera en la elección- la serie de actitudes y confianzas en el encargo, el reconocimiento, la legitimación, que el mejor representante politico puede llegar a significar para su electorado. Es un caso de expectativas y de esperanzas. El precio de esto no puede ser para el electorado el mismo, no obstante.

Dice Foessel comentando la jugada que, cuando "se evalúa el poder de la comunicación únicamente según el patrón de las campañas electorales, [en las que de hecho] la escenificación de uno mismo ha acabado por entronizarse [...] [Olvidamos no obstante que] cuando la atmósfera de campaña se ha disipado [...] la opinión pública no admite que un presidente se siga comportando como un candidato". De lo contrario, dicha opinión pública se sentirá políticamente ofendida. Y aclara acto seguido qué quiere decir con eso: "ofreciendo [al reconocimiento público] cotidianamente el espectáculo de su persona y de su vida" ${ }^{15}$. El poder conferido [conferred power], comunicado para erigir la cosa común, debe ser juzgado en base a los criterios de un segundo momento de la representación. Debe ser medido en su vigor en otro plano.

\footnotetext{
${ }_{14}$ Ibid., p. 189. Tanto la representación descriptiva como la simbólica se encardinan en el intento de conservar y promover lo diverso. Cf. con Goodin, R. E., "Representing Diversity", en British Journal of Political Science, vol. 34, no. 3, 2004, pp. 453-468.

${ }^{15}$ Foessel, M., op. cit., p. 11
} 
Lo que vale en campaña para la designatio es evaluado con severidad poco más tarde. La libre designación no es sino un inicio. El magistrado, el oficial, el consejero, y con mucha mayor razón el jefe del Estado, han de rendir cuentas de forma cumplida a sus votantes. La opinión pública no aprueba otra cosa. Foessel bautiza el ejercicio inmaduro de esa representación que morosa querría quedarse por siempre en la etapa de la candidatura uno de 'pipolización'16. De 'people'. El pueblo llano. La gente. La exhibición del político como individuo popular lo suficientemente parecido a su prójimo. La dosis del remedio a la infrarrepresentación es aquí un exceso. Es una muy mala traducción. Es mala traducción en lo que infantiliza la lengua que habla la opinión pública: esta necesita un vocabulario -signos civiles- pero debe articular una gramática después para decir con él lo que desea decir. Las posibilidades que esa gramática de la representación garantiza están en comprender que la inteligibilidad del siguiente momento de la lengua política pasa por cambiar la designatio por una elocutio. Una serie de la ratio. Las representationes discretas deben ampliarse para dar cabida a su articulación. Que muchos casos importen en uno solo. Muchas voces se digan en una sola. La 'pipol' en lo que se significa se estaría significando representativamente, sí, pero no ya políticamente. Hay significaciones representativas que no son más políticas. Cuando se confunden ambas categorías tenemos una segunda oportunidad para sentirnos ofendidos políticamente. Dice Foessel que "lo íntimo designa [justamente] un conjunto de vínculos que un individuo decide sustraer [esto es, hurtar] del espacio social de los intercambios" ${ }^{17}$. Un interés que no entra de esta manera como signo civil.

\section{Representación política ampliada, salus populi y obligación}

Si nos Jugamos lo QUe hemos PUesto en lo COMÚN, lo que podemos, nuestra abundancia y riquezas igualmente, lo menos que podemos reclamar es una interpretación prudente del retorno por parte del individuo -o la asamblea de ellos- que hace de foco del mandato en el que las hemos conferido. A ése -a ésos- es a los que se les piden cuentas en buena lógica. Dicha interpretación prudente es con necesidad dependiente de razones -frutos estas de la equidad [equity], que es connatural al ser humano ${ }^{18}$.

\footnotetext{
16 Ibid., p. 9

${ }^{17}$ Ibid., p. 14. Las ideas de Foessel sobre lo íntimo tienen su precedente en un artículo periodístico publicado por él mismo en Febrero de 2008 en la revista Esprit y titulado "La trivialisation de l'intime". Puede consultarse aquí: <https://esprit.presse.fr/article/michael-foessel/la-trivialisation-de-l-intime-14411>

${ }^{18}$ Hobbes, T., Op.cit., p. 86
} 
Esto aquí dicho vale lo mismo que afirmar que la confianza legítima está siempre sujeta a correcciones. Tan pronto como se transforma la naturaleza de la relación entre representante y representado cambia el signo de la misma confesión. La confianza es un bien [good] de la civitas. Es la vida de la misma que revierte en su unidad sustancial. Así, como en el infante que está aprendiendo una lengua y es corregido en el uso de la misma, se endereza la relación fidel en la ciudad. 'Asi se aplica ese término, asi se usa ese concepto'. 'En tales-y-tales circunstancias debes hacer tales-y-tales cosas'. El representante que queda más allá del candidato está sujeto a un encargo, a un mandato, y los pormenores del cumplimiento del mismo son revisables. La promesa, el juramento, el pacto, se hacen en previsión de... no como aprobación de... La distancia está en su acuerdo con el cumplimiento futuro. Estos pormenores y el mismísimo encargo son susceptibles de corrección, son susceptibles hasta de anulación - de revertir la representación y hacerla nula. El momento constitutivo deja paso así a uno regulativo. Al momento de la praxis. Porque el gesto enérgico es diferido y prestado. Como muestra, téngase en cuenta que Hobbes añade un particular subtema al título de su obra: el Leviathan trata sobre la materia, forma y poder de una República, sí, pero de una eclesiástica -esto es, con un adentro natural anímico para la libertad de conciencia-y civil-con un afuera público para las responsabilidades contraídas con otros y que otros contraen con nosotros para su articulación. La palabra del ser humano no tiene el mismo efecto que la divina aunque la imite. La palabra de aquél se constituye y regula a la vez como una designatio. La de éste es un sucedáneo -imitatio- del power, del might, del to make... y tiene que avenirse a lo que se compromete. "Un miembro cualquiera del Parlamento, a pesar de no parecerse en nada a un sindicalista, ni de haber sido designado por sindicato alguno, podría por una u otra razón preocuparse de continuo de los intereses de los sindicatos, como opuestos a otros posibles intereses. El sentido en el que ejercería de representante no sería -o no necesariamente- el que refiere a determinada clase o persona, sino el que refiere a determinados intereses. A esto llamaremos representación de intereses" ${ }^{19}$. Por una u otra razón, pero no por ninguna razón o en ausencia de razones. La representación de intereses entra en el terreno de las obligaciones contractuales. De la misma manera, el representante legal de un individuo no tiene por qué parecérsele en absoluto. "Lo representa en virtud del hecho de que lo que hace o lo que decide compromete a su cliente. A esto lo llamaremos representación ascriptiva" 20 .

\footnotetext{
${ }_{19}$ Griffiths, A. P.; Wollheim, R., Op.cit., pp. 189-190

${ }^{20}$ Ídem.
} 
Nuestro autor inglés de cabecera, por ejemplo, distingue para articular estas representaciones de Derecho entre ius [derecho] y law [ley]. "La libertad [liberty] que todo individuo tendría, para disponer de su propio poder, a su antojo, para la preservación de su propia naturaleza; esto es, de su propia vida" es el derecho $\left[\right.$ right, ius] natural en propiedad para el ser humano ${ }^{21}$. Sus abundancias y riqueza, su vigor y fuerza. Su vida. Libertad [liberty] es ausencia de impedimentos -dice Hobbes. Descarga de energía sin obstáculo. Fluida en su poder. Todo esfuerzo contrario que la disminuya o coarte es injusto de acuerdo a su juicio, y a lo que la razón le va a dictar [according as his judgment, and reason shall dictate him]. Daría motivo como para ofenderse de ser mal traducido semejante ímpetu. ¿Pero en base a qué? En base a su juicio y a lo que la razón le va a dictar. "Un programa político apenas tiene posibilidades de persuadir si no adopta la dimensión de una promesa, pero ya no dirigida a la nación considerada como un todo, sino a cada uno de nosotros tomados aisladamente" ${ }^{22} \mathrm{El}$ representante nos promete. Se nos promete. "Se representa también en su capacidad para aparecer como [...] creíble [en relación] a lo que somos o nos gustaría ser" 23 . A lo que tenemos y nos gustaría tener. Nos propone algo. De propositio en su doble sentido: 'proposición' como algo puesto delante en tanto bien y algo dicho en tanto intención. La law [ley, lex] es la regla general que prohíbe lo nocivo para la salus populi ${ }^{24}$. Que promueve el mantenimiento de los bienes [goods], las fuerzas de vida. Y representa esto la defensa del contrato pactado. Dicha defensa no juzga sino expectativas. Lo que la razón le va a uno a dictar, lo que va a prever. Juzga, de hecho, las disposiciones de los actores respecto de las expectativas que forman. Juzga -en definitiva- el futuro. Tenemos razones de peso para sentirnos políticamente ofendidos si es que se nos ha defraudado en nuestras expectativas a futuro. Es el contrato, el pacto, la promesa, el signo civil de la confianza, y esta se mantiene por la satisfacción de la citada expectativa. Tenemos razones para ofendernos pues la entrada en el contrato, en el pacto, en la promesa, tiene naturaleza voluntaria. Tiene por tanto carácter moral ${ }^{25}$. La obligación contraída es la sujeción por la cual razón y voluntad en su vagabundeo se encaminan por recompensa y castigo en pos del cumplimiento de su deber.

\footnotetext{
${ }^{21}$ Hobbes, T., Op.cit., p. 86

22 Foessel, M., Op.cit., p. 22

${ }^{23}$ Ibid., p. 10

${ }^{24}$ Hobbes, T., Op.cit., p. 20

25 Este y no otro es el argumento directriz de la obra que se considera seminal en la teoría del contrato como promesa: Fried, C., Contract as Promise: A Theory of Contractual Obligation, Harvard-MA, Harvard University Press, 1990
} 
"Para las nueve los cuerpos principales de Popolac y Podujevo estaban ensamblados en lo esencial. En los distritos que se les habian asignado los miembros de ambas ciudades estaban prestos y esperando para unirse a sus expectantes torsos [...] En el cuerpo columbrado de Podujevo empezaron no obstante a hacerse aparentes ciertos problemas técnicos [...] Gritaba Podujevo: un grito de muerte. Alguien enterrado en el flanco más débil habia comenzado la cadena del desmoronamiento del sistema. Alguien habia perdido al vecino y el vecino habia perdido a su propio vecino, propagando el caos a través del cuerpo de la ciudad..."

Clive Barker, En las Colinas, las Ciudades ${ }^{26}$

${ }^{26}$ Barker, C., "In the Hills, the Cities", en Books of Blood, vol. I, New York, Berkeley, 1986, pp. 187-188. La historia que Barker describe -en realidad está fechada en 1984- tiene como protagonistas dos ciudades de la Yugoslavia rural, Podujevo y Popolac. Cada diez años ambas emprenden el ritual de formar enormes gigantes tan altos como rascacielos - con cinchas y arneses que unen a más de cuarenta mil personas- para encontrarse en las montańas. Recuerda esto las celebraciones de gigantes y cabezudos de gran parte de la geografía española, estructuradores de lo social en la tradición. En el cuento de Barker, sin embargo, ese año algo va mal. Podujevo se desmorona y la catástrofe se lleva a gran parte de su población. Peor es el destino de Popolac, que ante la debacle del vecino pueblo enloquece y arrastra sin alma a sus ciudadanos, perdiéndose en las colinas más cercanas. El cuento se narra en su momento álgido desde la perspectiva de una pareja de turistas norteamericanos, Mick y Judd, que encuentran a la ciudad demente vagando sin rumbo a pesar de que casi todos sus miembros han caído ya también presa de la extenuación. Linda Badley ha desarrollado de manera exquisita las lecturas de Foucault que se encuentran a la base de ésta y otras historias de Barker -como no podía ser sino en "The Body Politic" (1984), en el volumen 4 de los Book of Blood, en que lo que sucede es que una misteriosa consciencia se despierta en todas nuestras manos, que se revolucionan y tratan de independizarse del resto de nuestros cuerpos- (vid. Barker, C., "The Body Politic", en The Inhuman Condition: Tales of Terror, vol. 4 of Books of Blood, New York, Simon \& Schuster-Poseidon, 1986, pp. 57-102). La referencia del capítulo dedicado a Barker por Badley es Badley, L., "Clive Barker Writing (from) the Body", en Writing Horror and the Body: The Fiction of Stephen King, Clive Barker and Anne Rice, Westport, Connecticut-London, Greenwood Press, 1996, pp. 73-104. 


\section{ReferenCias Bibliográficas}

Badley, L., "Clive Barker Writing (from) the Body», en Writing Horror and the Body: The Fiction of Stephen King, Clive Barker and Anne Rice, Westport, Connecticut-London, Greenwood Press, 1996, pp. 73-104.

Barker, C., "In the Hills, the Cities», en Books of Blood, vol. I, New York, Berkeley, 1986, pp. 172-210.

— «The Body Politic», en The Inhuman Condition: Tales of Terror, vol. 4 of Books of Blood, New York, Simon \& Schuster-Poseidon, 1986, pp. 57-102.

Biral, A., "Hobbes: la sociedad sin gobierno», en Duso, G., El contrato social en la filosofía politica moderna, Valencia, Leserwelt, 2002, pp. 51-108.

Foessel, M., «La trivialisation de l'intime», en Esprit: Comprendre le mon qui vient, Février 2008.

$<$ https://esprit.presse.fr/article/michael-foessel/la-trivialisation-de-l-intime-14411>

Foessel, M., La privación de lo intimo. Las representaciones políticas de los sentimientos, traducción de Jordi Terré, Barcelona, Ediciones Península, 2010.

Fried, C., Contract as Promise: A Theory of Contractual Obligation, Harvard-MA, Harvard University Press, 1990.

Goodin, R. E., «Representing Diversity», en British Journal of Political Science, vol. 34, no. 3, 2004, pp. 453-468.

Griffiths, A. P.; Wollheim, R., «How Can One Person Represent Another?», en Proceedings of the Aristotelian Society, Supplementary Volumes, vol. 34, 1960, pp. 187-224.

Hobbes, T., Leviathan, edited with an introduction and notes by J. C. A. Gaskin, Oxford, Oxford University Press, 1998.

Hoffe, O., Thomas Hobbes: Antropologie und Staatsphilosophie, Freiburg, Universitätsverlag, 1981.

Honneth, A., The Struggle for Recognition: The Moral Grammar of Social Conficts, translated by Joel Anderson, Cambridge, Polity Press, 2005.

- Reification: A New Look at an Old Idea, edited by Martin Jay, Oxford, Oxford University Press, 2008. 
Malherbe, M., Thomas Hobbes ou l'oeuvre de la raison, Paris, J. Vrin Librairie Philosophique, 2000.

Pitkin, H. F., The Concept of Representation, Berkeley, Los Angeles - CA, University of California Press, 1972.

DOI: http://doi.org/10.15366/bp2019.20.006

Bajo Palabra. II Época. No20. Pgs: 107-124 